\title{
Evaluation of the efficiency of the consolidation treatment with Paraloid B72, performed on artworks with degraded wood support
}

\author{
Constantin Ștefan Ionescu ${ }^{1,}{ }^{2 *}$, Aurel Lunguleasa ${ }^{1}$, Anamaria Avram ${ }^{2}$, and Cosmin \\ Spîrchez ${ }^{1}$ \\ ${ }^{1}$ Transilvania University of Brașov, Faculty of Wood Engineering, 500036 Bulevardul Eroilor 29, Brașov \\ ${ }^{2}$ Laboratory of Research and Restoration "Restaurare Ionescu Constantin", 550234 Henri Coandă 12, Sibiu
}

\begin{abstract}
The aim of the study is to determine the efficiency of the consolidation treatment with Paraloid B 72, performed on wood degraded by biological attack. The method of determining the HM hardness is an original scientific method, that is minimally invasive and which indicates the level of damage to the substrate before the consolidation treatment and at the end of consolidation, allowing the evaluation of the process. The specimens are tested with the Mark 10 apparatus to determine the HM hardness, which can be related to a standardized hardness. Two consolidation steps are performed in Paraloid B72, 12\% solubilized in Mixture (Ethyl Acetate and Toluene, $1: 1)$. At the end of the consolidation, the hardness increases from $6.74 \mathrm{~N} / \mathrm{mm}^{2}(37.11 \%)$ to $13.73 \mathrm{~N} / \mathrm{mm}^{2}(75.61 \%)$, compared to a reference wood, which has a hardness of $18.16 \mathrm{~N} / \mathrm{mm}^{2}$.
\end{abstract}

\section{Introduction}

Goods of art with wooden supports are subject to a process of evolutionary, natural deterioration, in conditions of controlled environment, or accentuated deterioration, in an improper environment or inadequate conditions of storage and exposure. In the historical course of the cultural heritage asset, a number of factors influence, the preservation or, as appropriate, the deterioration of works of art with wooden support. The natural aging of materials caused by time, produces stress at the level of composites, individually or as a whole of the art good. Wood is an anisotropic hygroscopic material, humidity and temperature are factors that change the dimensional stability as well as the installation and development of insect activity [1]. The consequence of the variations of humidity and temperature is manifested by dimensional instability, swelling/contraction, differentiated at the level of the support, the preparation layer (primer) or the polychrome layer (painting, inlay, marquetry). Each of them behaves and has a different response to the environmental and stress factors to which they are subjected. Uncontrolled humidity causes the loss of adhesiveness and cohesiveness of the composite material of the work of art, causing damage or destruction.

*Corresponding author: restaurareionescu@gmail.com 
The damage caused by various factors is difficult to control and can be incompletely and incorrectly assessed [2]. Knowledge of the structure of materials, causes and pathogens are important in order to understand the mechanisms of wood damage.

Xylophagous insects inflict, perhaps, the most important degradation to the cultural heritage goods with wooden support. In many cases, the biological degradation process is symbiotic, the insect attack is taking over a previous area attacked by xylophagous fungi [3]. Wood degradation must be interpreted by observing several aspects related to the factors that cause it, its consequences, the purpose for which the wood is used [2].

Research in the field of wood engineering and wood conservation/restoration of works of art aims to observe and evaluate the damage caused by wood-eating insects, but also to establish a treatment, depending on the level of damage. All of these are subject to or sometimes even limited by heritage conservation legislation, in terms of invasiveness or the possibility of extracting fragments large enough to be able to make structural or mechanical strength determinations in accordance with the standards in force (reported in healthy wood).

In the last quarter of the century, the technical evolution has allowed the development of investigations that evaluate the composition of materials, but also the "health" of the art object.

These investigations are performed with non-invasive equipment (X-ray fluorescence (XRF), X-ray radiography (RX), X-ray computer tomography (CT), semi-destructive [4] or minimally invasive $[1,5]$, also for the field of cultural heritage, it may be necessary to develop specially designed tomographic systems [6].

However, regarding the standardization for art objects that show complex damage, it lacks distinct specifications $[7,8]$.

Ionescu [2], develops a way to evaluate and rank the level of degradation caused by wood-eating insects, as well as methods by which these determinations can be made.

When the cultural heritage asset suffers severe degradation caused by xylophagous insects, most of the time, the existence of the composite can be endangered (wooden support, but especially artistic creation - as a historical cultural message), (fig. 1).
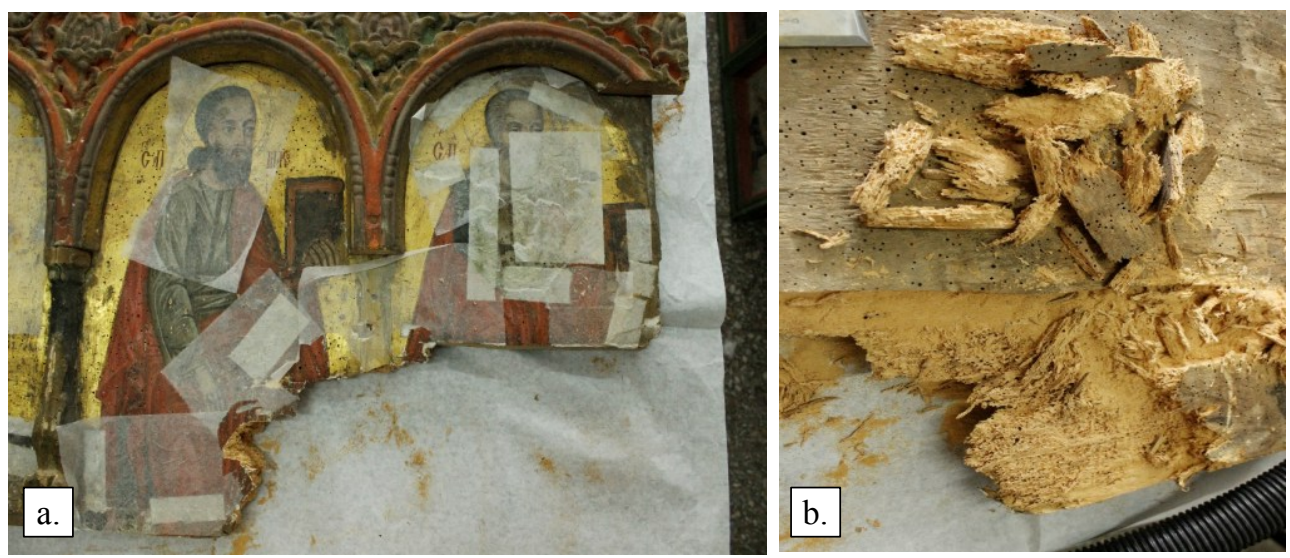

Fig. 1. Loss damage from xylophagous insects: a. polychrome front view; b. back view.

The assessment of the level of deterioration, as well as the efficiency of the consolidation treatment performed for wood from cultural goods, can be done by determining the physical parameters [11], but also by mechanical determinations - hardness being one of the important parameters.

Hardness is influenced by anisotropy and hygroscopicity and decreases with density. The hardness values also depend on the instrument used, for example, ball, cone, cylindrical tip, etc. [12]. 
The characterization and determination of some mechanical properties is a method of evaluating the response offered by a material - wood - subjected to the loading of some forces and which indicates the parameters of the tested material.

Hardness is the property of a body to withstand a mechanical action that tends to destroy its surface [14].

In this sense, on a fragile support, which reached a powdery state and when the anatomical elements of the wood are almost completely destroyed, consolidation treatments are applied, which aim to recover, improve and restore the physical and mechanical properties in order to prolong the life of these objects [9] (fig. 2).
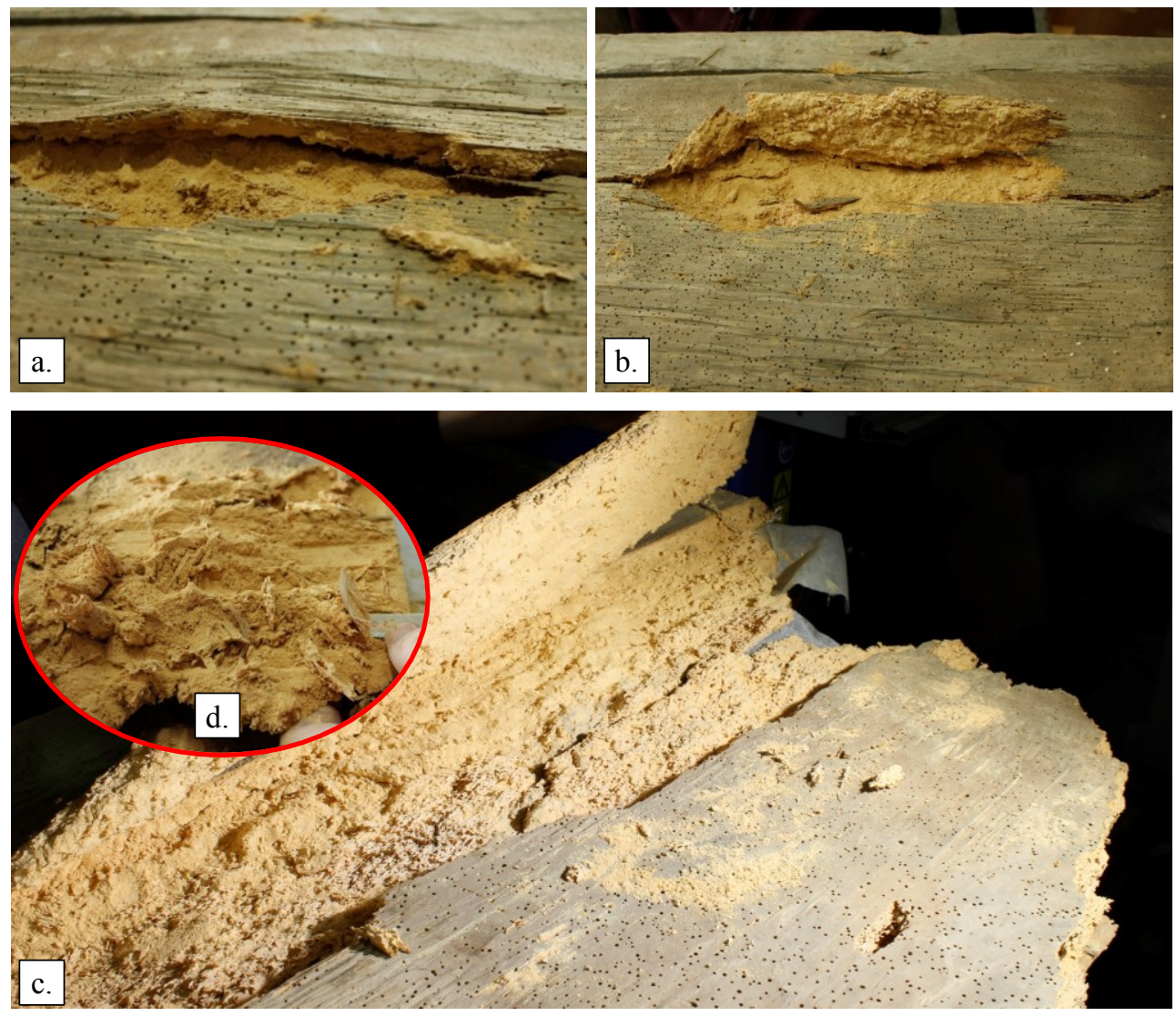

Fig. 2. a. b. c. d. Panel with xylophagous attack, strongly degraded, in powder state.

Wood consolidation is usually done with soluble resins; a common material widely used by conservators and restorers is Paraloid B72. However, structural improvements are not always evaluated [10].

The quality of the consolidation treatment can be influenced by the wood essence and its degradation state, by the type and method of treatment, by the viscosity of the consolidant and last but not least, by the number of repetitions of the treatment.

The presence and depth of penetration of a wood consolidant can be identified by physical determinations, and the efficiency of consolidation by mechanical measurements.

In this respect, the present research aims to contribute to the efficiency by measuring hardness during the course of consolidation treatment. 


\section{Objective}

Evaluation of the efficiency of the wood consolidation treatment from the cultural heritage goods, by reporting to the changes produced at structural level of the anatomical elements and/or on the physical and mechanical properties of the wood damaged by the xylophagous attack. The determination is performed by the method of measuring hardness (HM) with a sharp pin-like cylindrical penetrator.

\section{Materials, apparatus and method}

This study is developed in two directions, namely, small samples and a panel of an art object. Paraloid B72, in a concentration of 12\% solubilized in Ethyl Acetate and Toluene, 1:1 was used as consolidating material.

In the last quarter of the 21 st century, the technical evolution has allowed the development of investigations that evaluate the composition of materials, but also the "health" of the art object.

1. A set of seven very damaged lime wood specimens (tillia cordata) was used, with the following dimensions: $23.87 \times 20.16 \times 21.08 \mathrm{~mm}$, fig. 3 . The specimens (dating from the 18 th century) were extracted and recovered from elements of no structural or aesthetic importance, the position of which, in the whole of the iconostasis, could not be concretely established. Six of the specimens were immersed in consolidant solution for 24 hours, and one remained a benchmark; subsequently, they were extracted, weighed and allowed to evaporate the solvent for 14 days, after which, each type of hardness was determined.
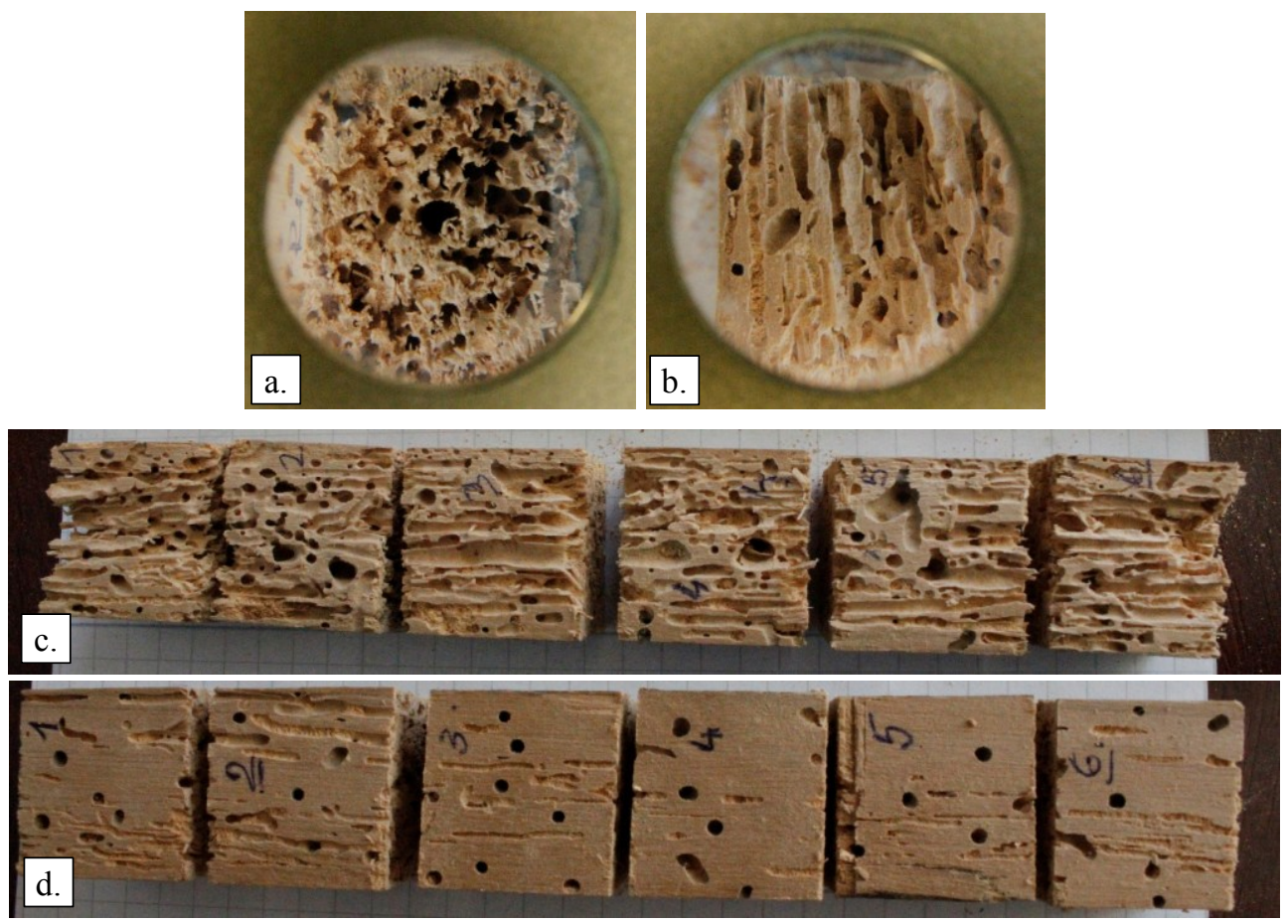

Fig. 3. Test tubes before treatment: a. cross section, with magnification of $10 \mathrm{x}$; b. radial section, magnified by $10 \mathrm{x}$; c. tested specimens - view on radial section; $d$. tested specimens - view on tangential section. 
2. The treatments and hardness determinations were done on the back, made of very damaged linden wood (tillia cordata) of a frieze that is part of an iconostasis, dating from the 17 th century (fig. 4). The panel has the dimensions 1815 x $455 \times 23 \mathrm{~mm}$. This panel was given a two-stage consolidation treatment, at a 3 months interval between the two, totalling $840 \mathrm{~g}$ of solid mass of Paraloid B72. In the panel volume of $18990 \mathrm{~cm}^{3}, 7980 \mathrm{~cm}^{3}$ of consolidating solution were introduced $(42.02 \%$ of the panel volume). The hardness of the panel was measured before consolidation $\left(\mathrm{H}_{0}\right), 3$ months after drying the first treatment $\left(\mathrm{H}_{1}\right)$ and at the end of the second treatment, after another 3 months after the treatment $\left(\mathrm{H}_{2}\right)$.

As a control benchmark, density and hardness measurements were made on a new healthy wood of the same essence and with the same $12 \%$ humidity.

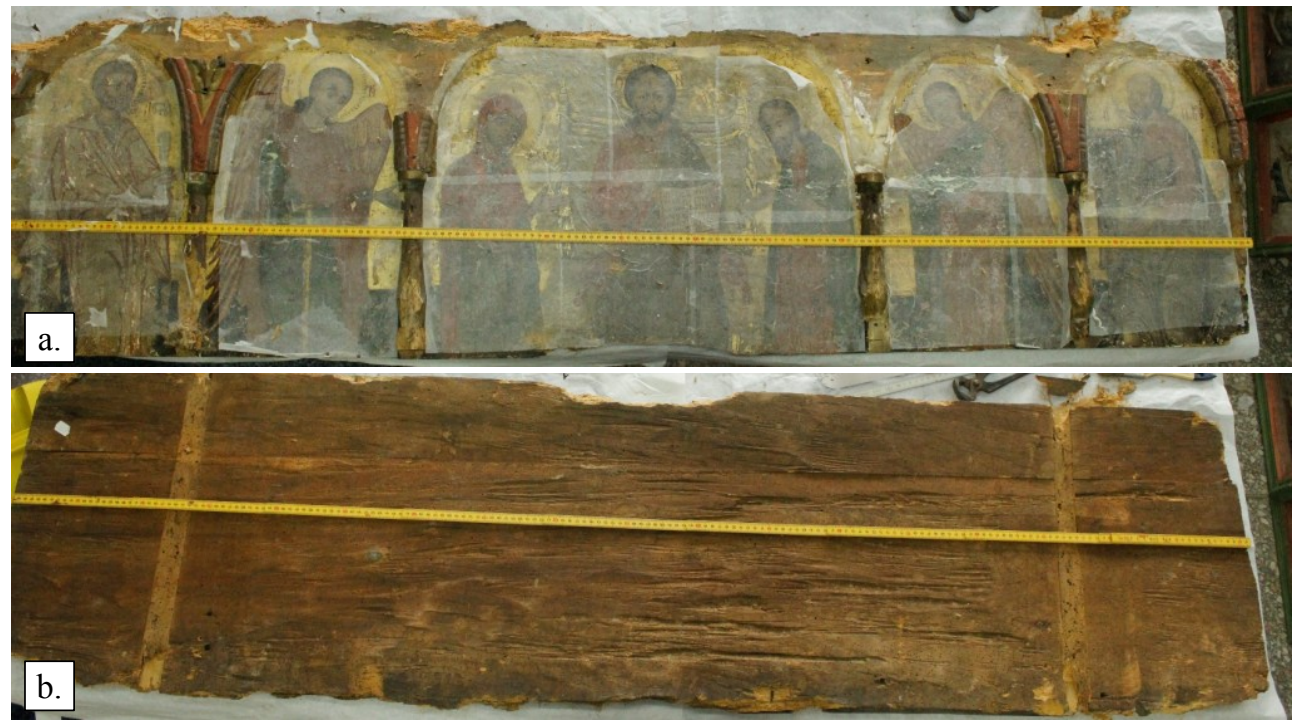

Fig. 4. 17th century panel, before treatments: a. painted front view; b. back view.

Determination of HM hardness is performed with an original scientific method, that is minimally invasive, for measuring, recording, and comparing the obtained values. The hardness test, with the Mark 10 dynamometer, is based on the wood penetration of a cylindrical tip with a diameter of $1.34 \mathrm{~mm}$ and a length of $6 \mathrm{~mm}$, with a pressing force indicated on the digital screen, expressed in $[\mathrm{N}][2,5,13]$.

Since the dynamometer does not have such a test tip, it was specially designed by the authors, precisely to be used in testing the hardness of works of art, since the mark left by the tip is as small as a xylophagous insect's hatching hole.

The dynamometer can be attached to a rack device (fig. 5) or used freely, detached from the device, in this way, through the freedom of action, the determinations are facilitated directly on the art object, no longer necessary to take samples for testing.

To obtain the hardness value, which can be correlated and compared with a standardized method (Brinell hardness) [2, 5], the calculation formula (Equation 1) was developed to obtain the Mark hardness (HM).

$$
H M=\frac{2 \cdot F}{A_{\text {l total }}}=\frac{2 \cdot F}{21.28} \mathrm{~N} / \mathrm{mm}^{2}
$$

where, $\mathrm{HM}$ - hardness marking, in $\mathrm{N} / \mathrm{mm}^{2}$

$\mathrm{F}$ - the force read on the Mark 10 dynamometer, in $\mathrm{N}$

$A_{1 \text { total }}$ - the total lateral surface of the tip penetrator, determined as a sum of the cylindrical and conical part $\left(21.28 \mathrm{~mm}^{2}\right)$, constant for all determinations in this research. 

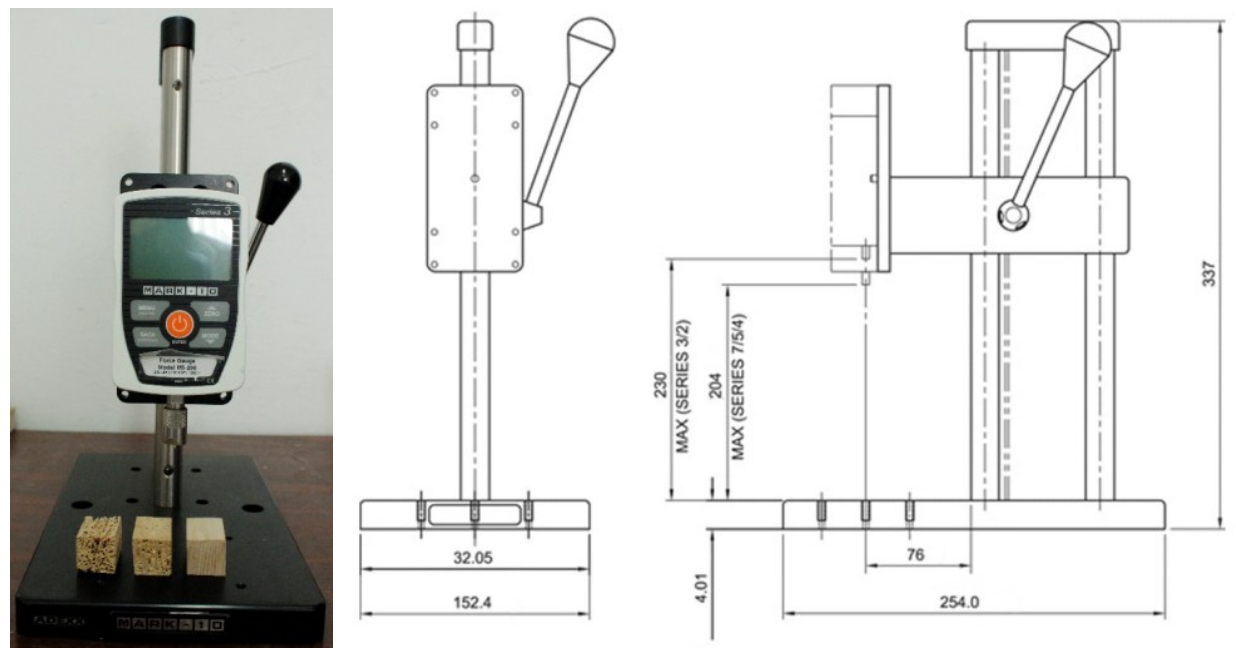

Fig. 5. Representation of the stand size for the Mark10 dynamometer (adapted after https://www.mark-10.com/instruments/stands/es10.html)

Mark hardness is proposed by the authors, adapting, for the Mark 10 stand and dynamometer, a sharp cylindrical tip (fig. 6) to test the degraded wood. Equation (1) proposed by the authors was also based on the standard Brinell hardness calculation formula [15].

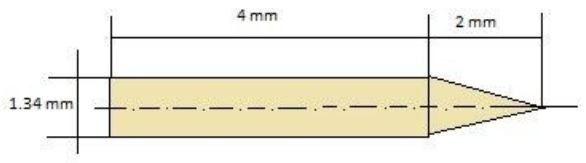

Fig. 6. The shape and size of the Mark 10 penetrator, as per $[2,5,13]$.

The device also has software that correlates data processing between peak penetration time and actuation force. The graphical representation (fig. 7) of the pressing force (F) in $[\mathrm{N}]$ and the time (T) expressed in [s], as necessary for the tip of $\varnothing 1.34 \mathrm{~mm}$ and length of $6 \mathrm{~mm}$ to penetrate the wood, highlights the development of the total force and the representation of the values, discharged differently on a time level, which attests to the fact that the penetration is not unitary and the force is not constant.

\section{Results and discussions}

The assessment of the deterioration of wood involves the investigation of its physical and mechanical properties, which usually require destructive sampling and a large number of samples in order to obtain conclusive data [8]. This study analysed the efficiency of the consolidation, using a minimally invasive assessment method, based on hardness determination (HM) with the Mark 10 dynamometer, which can be used directly on the heritage object, without the need for sampling.

A similar method was developed by Petrou and Pournou [8] for measuring hardness, with a fruit penetrometer, applicable to archaeological wood (waterlogged). The authors do not explain the calculation and evaluation method, nor the unit of measurement, or whether the values obtained can be correlated with a standardized hardness. 


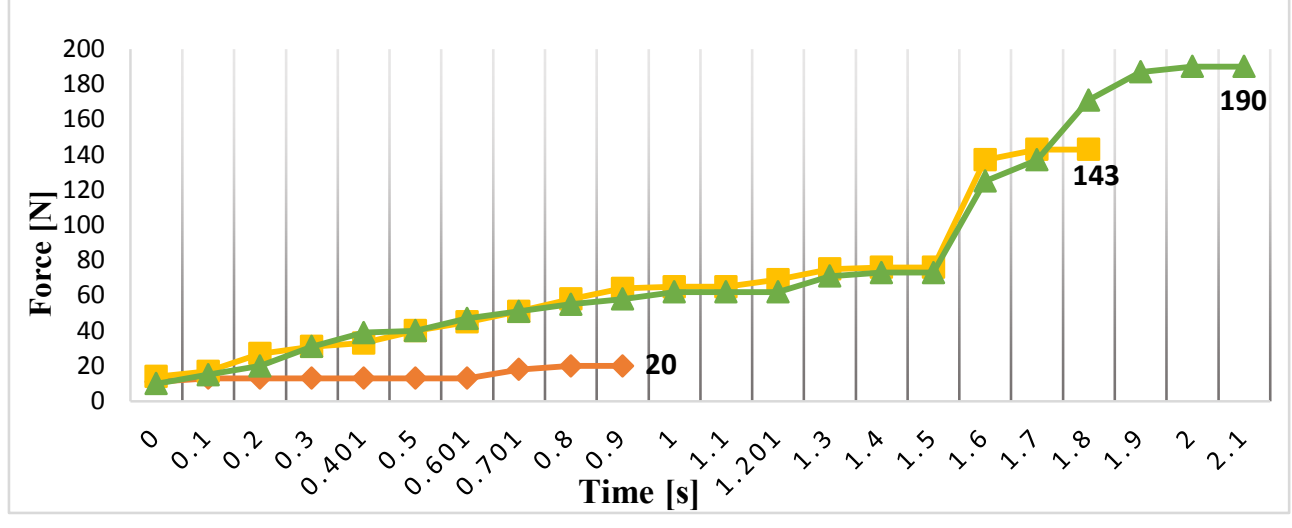

Fig. 7. Pressure values for highly degraded wood in different stages of treatment:

very degraded lime wood without treatment $(20 \mathrm{~N})$

very degraded lime wood with treatment B72.10\% (143 N)

highly degraded lime wood with double treatment of 10 and $20 \%(190 \mathrm{~N})$

The method developed by us refers to the determination of hardness for heritage objects which have suffered significant damage caused by wood-eating insects. This method also offers relevance for the evaluation of consolidation treatments, and through the hardness method, a hierarchy of damages has been developed, on degradation levels [2].

Hardness can have different values, on different areas of the same panel (even in the case of new, healthy wood), depending on the intensity of the attack of wood-eating insects. Therefore, it is recommended that the measurements be made in several areas on the entire surface of the panel, and the final reporting be made to the average of the values of all measured areas.

The distribution of the consolidant is not unitary and uniform throughout the panel; only a general increased density can be observed compared to the moment prior to treatment. Density measurements performed immediately after consolidation treatment, but also at an interval of 3 months after the end of treatment (when we assume that the solvent has completely evaporated) and comparison with the initial density, before treatment, do not correctly indicate an efficiency of the consolidation treatment. This statement can be demonstrated with the situation of the panel presented in this study - fragment of the $17^{\text {th }}$ century frieze; even if the density values are close, the mechanical parameters - in this case - the hardness, have not improved in the same proportion (see table 1).

Table 1. Panel densities $-17^{\text {th }}$ century frieze - estimated, damaged even after consolidation treatments.

\begin{tabular}{|c|c|c|c|}
\hline $\begin{array}{c}\text { Density }[\rho] \text { of the } \\
\text { new panel, } \\
\text { estimated }[2] \\
{\left[\mathrm{kg} / \mathrm{m}^{3}\right]}\end{array}$ & $\begin{array}{c}\text { Density }[\rho] \text { of the } \\
\text { panel before } \\
\text { treatment } \\
{\left[\mathrm{kg} / \mathrm{m}^{3}\right]}\end{array}$ & $\begin{array}{c}\text { Density }[\boldsymbol{\rho}] \text { of the panel } \\
\text { after the first } \\
\text { consolidation treatment } \\
{\left[\mathrm{kg} / \mathrm{m}^{3}\right]}\end{array}$ & $\begin{array}{c}\text { Density }[\rho] \text { of the } \\
\text { panel at the end of the } \\
\text { treatment }(\mathbf{T} 1+\mathbf{T} 2) \\
{\left[\mathrm{kg} / \mathrm{m}^{3}\right]}\end{array}$ \\
\hline 523.6 & 454.97 & 497.10 & 515.00 \\
\hline
\end{tabular}

Table 1 shows the densities of the damaged panel compared to a reference panel. If we observe the densities in table 1, it can be concluded that the difference in density between the reference panel and the damaged one (before treatment) is $15.08 \%$, and after the final consolidation treatment, it can be seen that the consolidated wood, from the point of view of the density is only $1.67 \%$ lower than the density of the reference panel, at $12 \%$ humidity. 
For the hardness determinations, the $17^{\text {th }}$ century frieze panel was divided into five equal zones, each with a surface area of 363 x $465 \mathrm{~mm}$; 10 measurements were made per zone, which resulted in an average for each of them, but also an overall average of the hardness of the entire panel (according to table 2).

Table 2. Hardness values for each measured area and overall panel hardness as a result of area averages.

\begin{tabular}{|c|c|c|c|}
\hline & $\begin{array}{c}\text { Initial hardness - } \\
\text { before treatment } \\
\mathrm{HM} \mathrm{N} / \mathrm{mm}^{2}\end{array}$ & $\begin{array}{c}\text { Hardness after } \\
\text { consolidation 1 } \\
\mathrm{HM} \mathrm{N} / \mathrm{mm}^{2}\end{array}$ & $\begin{array}{c}\text { Hardness after final } \\
\text { consolidation } \\
\mathrm{HM} \mathrm{N} / \mathrm{mm}^{2}\end{array}$ \\
\hline Zone 1 & 8.26 & 12.75 & 14.69 \\
\hline Zone 2 & 9.20 & 9.91 & 11.64 \\
\hline Zone 3 & 5.84 & 13.78 & 14.07 \\
\hline Zone 4 & 5.77 & 9.74 & 13.49 \\
\hline Zone 5 & 4.61 & 10.17 & 14.78 \\
\hline $\begin{array}{c}\text { Overall average } \\
\text { hardness/panel }\end{array}$ & 6.74 & 11.27 & 13.73 \\
\hline
\end{tabular}

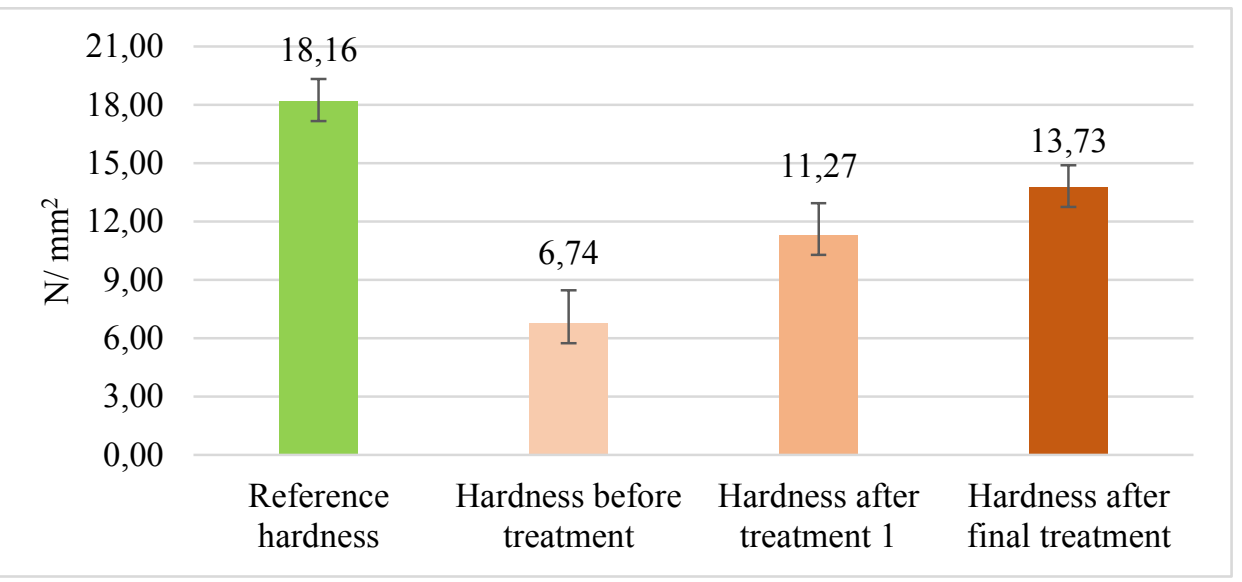

Fig. 8. Standard deviation for Mark hardness (HM) of $17^{\text {th }}$ century frieze panel, reinforced with Paraloid B72.

By analysing the two methods for determining the damage to the panel and the effect obtained from the consolidation treatment, we find that: in terms of densities (in Table 1) the damaged panel, compared to one of healthy wood, at the same moisture, has a loss of $15.08 \%$, and after the last consolidation treatment, the density differences are $1.67 \%$. Thus, it can be wrongly stated that the support at the end of the treatment is close to the reference value of the healthy panel and that the consolidation treatment is fully performed. Even if the panel has reached a density close to that of the reference panel, the mechanical parameters are not at the same level as those of the reference panel.

However, if we analyse the hardness values in table 2, we can see that the degraded panel, before treatment, has a hardness of $6.74 \mathrm{~N} / \mathrm{mm}^{2}$, compared to the hardness of a reference panel which has the value of $18.16 \mathrm{~N} / \mathrm{mm}^{2}$. This shows that the damaged panel has a hardness of $37.11 \%$ compared to the reference panel. At the end of the second consolidation treatment, the hardness improves by $2.46 \mathrm{~N} / \mathrm{mm}^{2}$, resulting in a consolidation efficiency increased by $13.54 \%$ compared to the previous stage. Analysing the efficiency of the treatment from the beginning to the end, we can see an increase in the final hardness, from $6.74 \mathrm{~N} / \mathrm{mm}^{2}$, to $13.73 \mathrm{~N} / \mathrm{mm}^{2}$ and a total consolidation efficiency by $38.48 \%$. 
If we compare the panel's hardness at the end of the consolidation process with that of the reference panel $\left(18.16 \mathrm{~N} / \mathrm{mm}^{2}\right)$ it can be shown that, after treatment, it has improved up to $75.61 \%$ of the value of the reference panel.

The study analysed and recorded the values for each of the five measurement areas of the panel, which showed increases in hardness and consolidation efficiency. In the present study, only the averages of these values were highlighted.

Regarding the experiment, compared to the specimens and analysing the values obtained for the six specimens immersed in the consolidant, the respective density and hardness can be observed in table 3. Five hardness values were measured on each test piece, and only their averages were noted in the table.

Table 3. Density and hardness of specimens before and after treatment.

\begin{tabular}{|c|c|c|c|c|}
\hline $\begin{array}{c}\text { Test tube } \\
\text { number }\end{array}$ & $\begin{array}{c}\text { Density before } \\
\text { treatment } \\
{\left[\mathbf{k g} / \mathbf{m}^{\mathbf{3}}\right]}\end{array}$ & $\begin{array}{c}\text { Density after } \\
\text { treatment } \\
{\left[\mathbf{k g} / \mathbf{m}^{\mathbf{3}}\right]}\end{array}$ & $\begin{array}{c}\text { Hardness before } \\
\text { treatment } \\
{\left[\mathbf{N} / \mathbf{m m}^{\mathbf{2}}\right]}\end{array}$ & $\begin{array}{c}\text { Hardness after } \\
\text { treatment } \\
{\left[\mathbf{N} / \mathbf{m m}^{\mathbf{2}}\right]}\end{array}$ \\
\hline 1 & 296.31 & 349.10 & 4.87 & 5.22 \\
\hline 2 & 270.82 & 321.18 & 4.82 & 7.85 \\
\hline 3 & 320.38 & 381.31 & 4.89 & 5.59 \\
\hline 4 & 319.29 & 384.16 & 5.11 & 7.99 \\
\hline 5 & 307.41 & 368.49 & 5.14 & 5.22 \\
\hline 6 & 298.35 & 354.10 & 4.43 & 6.06 \\
\hline $\begin{array}{c}\text { Medium } \\
\text { values }\end{array}$ & 302.10 & 359.72 & 4.88 & 6.32 \\
\hline
\end{tabular}

The average of the initial density values of the damaged wood specimens is $302.10 \mathrm{~kg} / \mathrm{m}^{3}$, and at the end of the treatment the density is $359.72 \mathrm{~kg} / \mathrm{m}^{3}$, which represents a $19.07 \%$ increase of the consolidated wood.

Regarding the hardness, the deteriorated specimens had, on average $4.88 \mathrm{~N} / \mathrm{mm}^{2}$, and after consolidation, the hardness increased to $6.32 \mathrm{~N} / \mathrm{mm}^{2}$, namely an improvement of $29.51 \%$ can be observed.

Analysing the two cases in which the wood attacked by xylophagous insects had an almost similar deterioration, we find that the wood from lower density specimens and a single consolidation treatment absorbed less consolidant, compared to the wood from the panel, which had multiple treatments and an increased density (closer to the reference density). This could be explained by the fact that the sawdust which accumulated in the galleries could be extracted from the specimens damaged by the xylophagous attack, while in the case of the panel, this was done in a much smaller proportion.

\section{Conclusions}

The reinforcing material can be identified by its presence and depth of penetration into the wood and can be determined by physical methods (FTIR, SEM). The improvement of mechanical parameters can be determined by performing hardness tests.

If in general, in the literature, archaeological wood is of particular interest, this research applies to cultural heritage assets that are degraded by wood-eating insects.

The intervention is minimally invasive, the diameter of the measuring needle is smaller than the orifice produced by xylophagous insects or the tip of the humidometers, and the response produces concrete information about the condition of the material and the effectiveness of the applied treatment. 
Density measurements performed before, at the end or after a certain time in which the evaporation of the solvent occurs may indicate errors and even more neither the level nor the surface in which the consolidant has been distributed can be concretely highlighted.

Repeating the reinforcement treatment on art objects with heavily degraded wooden support, produces improvements in terms of hardness, which gives it increased resistance to manoeuvrability and exposure.

The method of determining degradation by differences in density, in the case of polychrome panels, may indicate errors caused by fractions of wood (sawdust) remaining in the larval galleries, which cannot be removed. These fractions, in addition to their own mass, absorb moisture, changing the density of the wood (panel mass). This is an additional argument for the development of alternative methods for detecting damage [2, 13], as well as those for assessing the effectiveness of consolidation treatments.

Following the consolidation treatments, it can be seen, however, that the maximum values obtained are lower than the reference hardness. Therefore, the minimally invasive method of hardness testing proposed in this research highlights the range in which mechanical properties improve.

Possible future directions of research would be new ways to determine and highlight the depth of penetration of the consolidant, but also the possibilities of measuring the efficiency of consolidation in the depth (in the thickness of the wood) of the consolidated and tested panel. Adaptation of non-invasive calculation methods, devices or devices for hardness testing, cultural heritage objects.

\section{References}

1. M. Mustață, Gh. Mustață, B. Ungurean, M. Moșneagu, G. Gămălie, L. Axinte, Etopatologia operei de artă, (Ed. Academiei Oamenilor de Știință din România, București, 2013)

2. https://www.unitbv.ro/documente/cercetare/doctorat-postdoctorat/sustinereteza/2020/constantin-ionescu/Rezumat_teza_Ionescu_Constantin_Stefan.pdf 02.10.2020]

3. B. Ungurean, Annals Series on Biological Sciences, 1, 5 (2012)

4. M. Drdácký, M. Kloiber, Advanced Materials Research, 778, 209 (2013)

5. C. Ș. Ionescu, A. Lunguleasa, C. Spîrchez, A. Avram, MATEC Web of Conferences 290, 01004 (2019)

6. M. P. Morigi, F. Casali, M. Bettuzzi, V. D’Errico, Applied Physics A, 100, 653 (2010)

7. N. Macchioni, C. B. Cestari, T. Tannert, In Situ Assessment of Structural Timber (Springer, Dordrecht, 2011)

8. M. Petrou, A. Pournou, WOAM 16, Testing the efficiency of a fruit penetrometer to assess the condition of small waterlogged wooden artifacts (Florence, Italy, 2016)

9. C. S.. Ionescu, A. Lunguleasa, Pro Ligno, 13, 447 (2017)

10. J. V. Oliver-Villanueva, J. E. Benitez-Telles, M. V. Vivancos-Ramon, J. V. Grafia-Sales, Wood Research, 57, 33 (2012)

11. P. Jensen*, D. J. Gregory, Journal of Archaeological Science, 33, 551 (2006)

12. M. Riggio, M. Piazza, Hardness Test. In: Kasal B., Tannert T., In Situ Assessment of Structural Timber (Springer, Dordrecht, 2010)

13. C. Ș. Ionescu, A. Lunguleasa, C. Spirchez, A. Avram, Pro Ligno, 15, 75 (2019)

14. I. Curtu, N. Ghelmeziu, Mecanica lemnului și materialelor pe bază de lemn (Ed. Tehnică, București, 1984)

15. EN 1534:2000, Wood and parquet flooring - Determination of resistance to indentation, Brinell Test method (2000) 